\title{
Product Placement And Consumer Brand Salience: Measuring The Impact
}

\begin{abstract}
Muhammad Ovais ${ }^{1}$, Dr. Muhammad Nouman ${ }^{2}$
Abstract

When the song 'Pass the Courvoisier' remained in Billboard's hot 100 music Chart for around 20 weeks in addition to significant exposures on TV and radio networks. To the surprise of marketers and advertizing practitioners was meanwhile a double digit in the sales of 'Courvoisier cognac' the basic theme of this song. Many more such examples appeared on the marketing communication horizon indicating that such practices may lead to a more effective brand communication relative to conventional advertizing. Following an experimental design, the focus of this research was to analyze and understand the role of brand placement on consumer recognition and recall (salience) of that particular brand. Consistent with the previous literature we found significant brand salience related implications of brand placement in Pakistani context. The findings however also suggest for careful management of the placement strategies. Our findings provide new academic insights into and a foundation for researchers in this regard.
\end{abstract}

Key Words: Product Placements, Logorama, Brand Salience

\section{Introduction}

\subsection{Background and Context:}

Busta Rhymes, the hip-hop musician, released in 2002, 'Pass the Courvoisier'. This song was present in Hot 100 music chart of Billboard for more than 20 weeks, reportedly shown for more than 620 times through the BET and MTV networks, and had the radio broad cost of over 97,000 times (Roberts, 2002). The sales of the song's basic theme subject 'Courvoisier cognac' increased by more than $10 \%$ during this time. The objective of the video game, Super Monkey Ball launched in 2001 is to gather as much bananas as may be probable inside a particular time edge while staying away from blockages and fighting enemies. Each and every banana is tagged with a sticker of the Dole Company (Emery, 2002). Similarly, challengers on the famous reality show, American Idol which is aired on Fox, wait in the Red Room of Coca-Cola for their turn on stage and the three judges of the show enjoy sipping out of cups carrying the logo of Coke. In its different forms, Product placement' is now operational as promotional mix's key arm recently. Industry deregulation has

1 Phd Scholar, Institute of Management Sciences Peshawar

2 Assistant Professor, Institute of Management Sciences Peshawar 
brought changes in media landscape in many countries together with global technology evolution and global reach.

The aim of this research was to measure and analyze the impact of product placement on brand salience that is, consumer level of awareness about a particular brand.

\subsection{Categories of Placement:}

The strategies of product placement are generally categorized into three major types: "implicit product placement, integrated explicit product placement and non-integrated explicit product placement". Implicit product placement points to the product placement within a television program while avoiding its formal expression, thus the role of brand is passive and contextual. For example, Friends which is a television series in US, a scene was there in which Rachel took off to London for the wedding of Ross in a Virgin plane. Branded products are frequently seen on various spots in the famous UK TV show EastEnders. In these programs there is however, no open reference to sponsorships in the credits or scripts. A formally expressed branded product within a television show is termed as an "integrated explicit product placement": where an active role is played by the brand. The attributes and benefits are clearly expressed and emphasized in this type of brand placement. For example, "characters in the pubs in UK shows Coronation Street, Emmerdale and Brookside choose Carlsberg when they want a drink"; Tom Cruise makes sip from Guinness in Minority Report. In "non-integrated explicit product placement" there is no integration in the movie content, of the branded product placed and formally expressed. They present the name of sponsor at the beginning, at the end or during the program; for instance, Bailey's sponsored "Sex and the City" and/or "A Mini drama with Cold Fee"'. Another categorization of Product placement can be in terms of its relevance and modality. The categories "screen placement, script placement and plot placement were employed by Russell (1998). Screen placement is the visual category of placement, involving brand placed in a movie scene or television show. The verbal or auditory placement is called script placement, mentioning the brand in a dialogue in movie or show. The combination of verbal and visual placements is called plot placement. In plot placement, the brand becomes a fraction of the plot or acquires a main position in the storyline. Current insight among the agents dealing brand placement in Hollywood movies is that, a story must be told by the expression of the brand simply 'portraying the can' might not present a amply influential narrative context to increase the identity if brand (Hackley, 2003).

\subsection{The objective of this Research:}

This research aimed to analyze the impact of brand placements; 
- In Pakistani Culture Context and

- On over all brand salience by measuring recall and recognition.

\section{Review of Related Literature:}

\subsection{Brand Placement; the underlying logic:}

A number of empirical studies performed on the advertising and performance relationship have come up strong proof that companies' traditional advertising campaigns yield positive shareholder return (Conchar, Crask, and Zinkhan, 2005). However, due to the increasing consumers' resistance to traditional media advertising, firms are largely opting for to alternative ways to get to consumers and increase their brands' value (Keller, 2001; Elliot, 2008). There is a wide belief that advertizing clutter reduces the effectiveness of advertising across media. Majority of media planners have the view that advertising clutter reduces a the effectiveness of the medium (Mandese, 1994; Chan- Olmstead, 1994). The audience is now skeptical and fragmented and does not consider conventional advertising as good (Young \& Sung, 2009).

Researchers define define product placement as "the inclusion of a product, a brand name, or the name of a firm in a movie or in a television program for promotional purposes (d'Astous and Chartier, 2000)." Product placement is sighted like a hybrid message because of its "hidden but" character (Balasubramanian, 1994). In fact, it can be called as promotion put forth in a non-promotional and entertainment context, such that the intentions of promotion are not explicit. The practices of putting branded products inside films for marketable purposes have grown into a distinctive promotional means as argued by Newell, Salmon and Chang (2006). The relatively fresh fame of the practices have come about because of their cost benefit ratio and prospective for extensive audiences in the form of ever enhancing prices of placement on the traditional, audiences' limited ability to skip exposure to the attempt of persuasion, savings in increasing marketing costs on filmmakers side (Motion Picture Association, 2007), and the aesthetic augmentation of settings which depict in the content of the film (DeLorme and Reid, 1999).

Another reason is that the sponsors too, know the need of the moviemakers for financial support, they attempt to take benefit of the chance to picture their products and brands to the audience. In addition, cost effectiveness pose as another factor of motivation for product placement relative to the exposure of the brand (Steorz, 1987; Vollmers and Mizerski, 1994; Howard-Williams, 1993). Long ago when E.T. was enthralled by Reese's Pieces of Hershey, brand placement has been considered as among the most efficient and effective tool of promotion because of its potential to 
increase sales, and this is proven by a large number of movies (Reed 1989; Galician, 2004; Russell, 1998, 2002; Lehu, 2007).

\subsection{Product Placement; Some Critical Reasons and Benefits:}

The first cause for the fresh fame of advertising professionals looking for potential opportunities to place their brands in movies and games is the cost efficiency of the exercise and the prospective for unlimited coverage, in view of the rapidly increasing prices of others medias (Wasko et al., 1993). Not only brands are seen and/or heard by audience with only a single placement in the film, but they reach even much broader and larger audience when the film is later watched on videos and DVDs, and is afterward also broadcasted on network televisions and cable TV channels. The benefits of brand placements are similar in other media. For example radios play popular songs on regular rotation, similarly, famous show on television show repeated telecasts usually in syndication. This is also true for video games which are played multiple times (Evangelista, 1999).

The financial aspect of brand placement is among the most appealing facets for the people like music producers, directors, video game developers, that are on the media's content creation side. The contracts of brand placement support in offsetting the production and marketing costs of the media products as argued by Evangelista (1999). The production and marketing costs of a Hollywood film at an average in 2003 reached to almost $\$ 103$ million, with the costs of marketing accounting for more than 37\% only ( $\$ 39$ million). Compared to average marketing/production (combined) costs of about $\$ 44$ million in 1993 (Motion Picture Association, 2004).

Similar is the case with the costs of video games, they are also rising, with an average production costs of $\$ 15$ million and $\$ 10$ million as costs of marketing for one game. Compared to 2001's $\$ 5$ million for production and $\$ 2$ million for marketing (Fritz and Graser, 2004). Therefore it is not shocking that developers of the content appreciate the role of brand placements more and more in reducing their spending, while maintaining sound advertizing level. It may be in the form of direct payment to creators, or through deals and contracts whereby brands such as hotels and cars are provided without cost in exchange for placement within the media content.

Several other aesthetic reasons are frequently cited for content developers to intentionally include real brand (elements), say for example to enhance the realism.

\subsection{Product Placement; Memory, Recognition and Recall:}

Enhancing brand awareness is one of the main benefits of brand placement for marketers, while simultaneously attaining extra exposure for their brand (Steortz, 
1987). The life span of an average movie is expected to be 3.5 years. Together with the digital/cable television and home video rental market, there is a potential for enduring and widespread exposure (Belch and Belch, 1998). Further, at the same time as brand awareness will enhance with simple exposure(the brand consciousness), it is suggested that when a particular brand's awareness increase, the awareness of the rival brand decreases (Alba and Chattopadhyay, 1986) and as a consequence the evoked mind set is modified (Moran, 1990).

Awareness leads the potential buyer to identify the brand or product and so supports the purchase process and will differ on a range of memory based course of actions from recall to recognition (Rossiter and Percy, 1983).

Human decision making involves memory processes to varied extent. At the same time as there exist a number of theoretical explanations attempting to explain the process, it is usually approved that the information that comes from the external environment to the brain moves through the "sensory memory into the short-term (or working) memory". The working memory then passes the salient information to the long term memory where, this information can be stored for ranging from several minutes to several years (Atkinson and Shiffrin, 1971). Then the memories are stored through linkages between existing and new memories in various portions of the memory. Later they are placed down in a framework allowing access to some memories easier than others. "Recall is the process by which an individual reconstructs the stimulus itself from memory, removed from the physicality of that reality (Atkinson and Shiffrin, 1971)". Therefore, cues for example, product category or scene from a movie may facilitate the recall of the brand stored within memory.

Recognition, however, needs a person to discriminate or differentiate the earlier acquired stimuli from a set of possibly distracting and extraneous stimuli. This may be relatively easier to attain compared to recall (Bettman, 1979). We used a comprehensive questionnaire adapted from the work of de Gregorio and Sung (2004) in order to measure brand salience (Recall and recognition).

\subsection{Literature Gap:}

Brand placement's discussions in the press and academic literature mostly spin around film. However, the recent content analysis work and the opening examples (Ferraro and Avery, 2000; de Gregorio and Sung, 2004; Friedman, 1991) reveal that appearances of brands within other media are apparent and continue to rise in occurrence as time advances. Although scholarly research on brand placement has been continuing since the last decade, there has been a shortage of inquiry of brand placement in non-film media (Galician, 2004; Lehu, 2007). Secondly as found out by 
Sung and Gregorio (2008), there exist significant differences among consumer attitude towards brand placements across media and media genres. Finally Cross-cultural investigations also reveal differences in consumers' response towards brand placement (Gould et al. 2000; Rossler and Bacher, 2002), as well as lesser acceptance of brand placement on ethical grounds among Singaporean respondents than among U.S. respondents (Karrh, Frith, and Callison, 2001).

\subsection{Hypotheses:}

H1. Brand Placement has positive association with Brand Recognition

H2. Brand Placement has positive association with Brand Recall

\section{Methodology:}

\subsection{Experimental Investigation:}

Experimental methods are usually employed by effectiveness studies, by first exploring consumer explicit (memory) and implicit (brand evaluation) measures through techniques like interview or often questionnaire then exposing them to the medium and after a short distraction they are queried again for the aforementioned measures with the technique (questionnaire) used earlier. The difference between the two readings that is pre and post medium exposure is actually considered to be the effect or influence of that medium upon memory and in turn brand salience (Law and Braun, 2004). Free and aided recall are the frequently used dependent measures (Babin and Carder, 1996; Karrh, 1994; d'Astous and Se' guin, 1999; Gupta and Lord, 1998) chased by recognition (d'Astous and Chartier, 2000; Babin and Carder, 1996; Law and Braun, 2000). Brand awareness being vital and fundamental in building brand equity is the primary objective of product placement. Therefore, measures based on memory are considered as appropriate method to test the effectiveness of product placement.

\subsection{Participant and Material:}

The experiment was completed in about 1 hour and 32 undergraduate, graduate and master level students were involved. Participants were informed that this experiment was aimed at rating and evaluating a popular cartoon movie related to marketing and branding (logorama). The rationale for the video was that all the selected students were either studying marketing either as specialization or at least one course subject in order to get uniformity of responses. The video was run in the TV room soon after dinner by attaching a Nokia N95 mobile to the TV set clearly visible to the viewers as shown in picture below. Through convenience sampling initially the questionnaire 


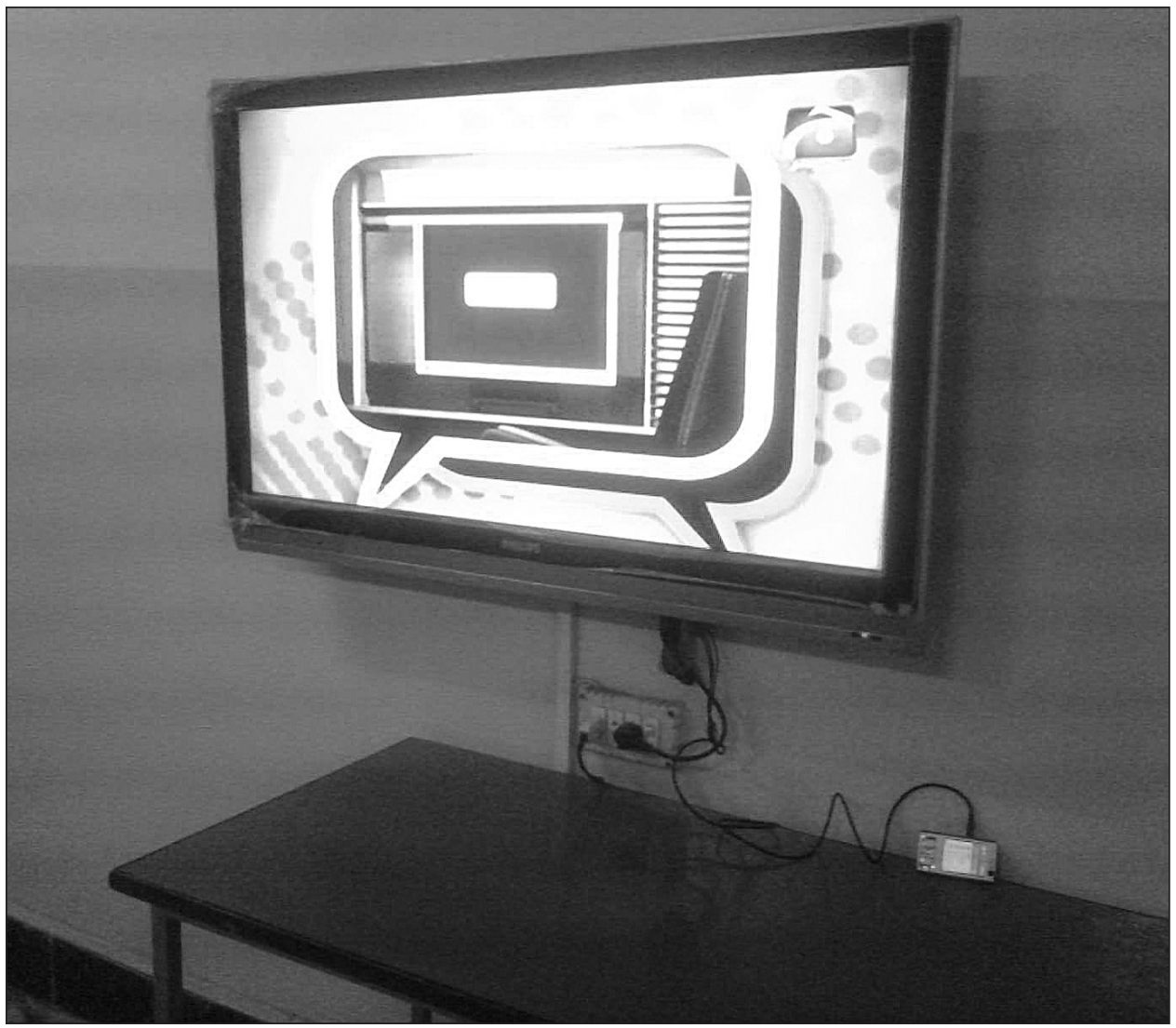

was delivered to the students at breakfast time and responses regarding brand (Nokia N95) awareness and recall were collected.

\subsection{Stimuli and Procedure:}

After a short time of distraction, questionnaire was administered again for memory response measures regarding brand awareness. After watching the film the respondents were immediately, asked to jot down and express their thought about the main objective of the study, to ensure that no one knew the real purpose. A comprehensive questionnaire the work of de Gregorio and Sung (2004) was used to collect pre and post exposure brand awareness and recognition measures.

Participants were well-versed that the intention of the experiment was to judge their assessment of that branding cartoon film named, Logorama. After watching the video, all the participants were requested to fill out a form for evaluation and rating of their overall assessment of the show, perception for the roles and characters in the cartoon clip, and the rate and duration of watching Logorama. 


\section{Results and Discussions:}

\subsection{Brand Recall:}

\subsubsection{Top of the Mind Brand:}

As mentioned earlier brand recall was measured by asking respondents about top of the mind set and most familiar brands. A post exposure improvement in the brand in question's (Nokia N95) respondents' top of the mind frequency was seen after the experiment. That is from 23 to 25 out of 32 respondents electing Nokia N95 as the top of the mind brand, showing an improvement of $3.2 \%$ as shown in table 1 .

\subsubsection{Brand Familiarity:}

We used Paired sample t-test to compare the pre-exposure and post exposure responses regarding the second aspect of the brand recall that is brand familiarity. The results as shown in table 2 show a significant post exposure improvement in the brand familiarity, with a t-value of 7.996 at a two tailed significance level of 0.000 at 95\% confidence level.

\subsection{Brand Recognition:}

For effective measurement, brand recognition was operationalized by 7 sub variables, namely use, choice, satisfaction level, recommendation, loyalty and ease of availability of the complimentary applications. Similar to brand familiarity, pre and post exposure responses were analyzed and compared through paired sample t-test. Once again significant post exposure improvement in brand recognition was found with a two $t$-value of 5.943 significant at a 0.000 at $95 \%$ confidence interval.

These results are in line with Soonkwan Hong et al. (2008) that product placement positively impacts the brand salience and improves both consumers' recall and recognition thus have a positive impact on brand equity.

\section{Conclusions:}

It can be concluded that product placement in fact enhances brand salience, if the practices are managed properly. Copious research has concentrated on the consumers' attitude towards product placements and/or their motivation to acknowledge and appreciate the apparently invasive marketing programs and actions. Contrarily, less scholarly research has focused on examining the appropriate procedures and techniques to present brands/products in the movie context. These findings furnish new academic insights and a foundation for future scholars via suggesting a new 
Table 1:

\begin{tabular}{|l|l|l|l|l|l|}
\hline \multicolumn{2}{|c|}{} & \multicolumn{2}{c|}{ Before Exposure } & \multicolumn{2}{c|}{ After Exposure } \\
\hline \multicolumn{2}{|c|}{} & Frequency & $(\%)$ & Frequency & $(\%)$ \\
\hline \multirow{3}{*}{ Valid } & Apple & 3 & 9.4 & 2 & 6.2 \\
\hline \multirow{7}{*}{} & Nokia & 23 & 81.2 & 25 & 84.4 \\
\cline { 2 - 7 } & Samsung & 6 & 100.0 & 5 & 100.0 \\
\cline { 2 - 7 } & Total & 32 & & 32 & \\
\hline
\end{tabular}

Table 2:

\begin{tabular}{|c|c|c|c|c|c|c|c|c|c|}
\hline \multicolumn{10}{|c|}{ Paired Samples Test for brand familiarity } \\
\hline & & \multicolumn{5}{|c|}{ Paired Differences } & \multirow[b]{2}{*}{$\mathrm{t}$} & \multirow[b]{2}{*}{ df } & \multirow[b]{2}{*}{$\begin{array}{l}\text { Sig. } \\
\text { (2-tail } \\
\text { ed) }\end{array}$} \\
\hline & & \multirow[t]{2}{*}{ Mean } & \multirow[t]{2}{*}{$\begin{array}{l}\text { Std. } \\
\text { Devia- } \\
\text { tion }\end{array}$} & \multirow[t]{2}{*}{$\begin{array}{l}\text { Std. } \\
\text { Error } \\
\text { Mean }\end{array}$} & \multicolumn{2}{|c|}{$\begin{array}{l}95 \% \text { Confidence } \\
\text { Interval of the } \\
\text { Difference }\end{array}$} & & & \\
\hline & & & & & Lower & Upper & & & \\
\hline $\begin{array}{c}\text { Pair } \\
1\end{array}$ & $\begin{array}{l}\text { Which of } \\
\text { the brand } \\
\text { you are fa- } \\
\text { miliar with? } \\
\text { - Which of } \\
\text { the brand } \\
\text { you are fa- } \\
\text { miliar with? }\end{array}$ & 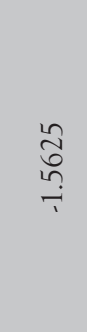 & $\begin{array}{l}\hat{n} \\
\stackrel{-}{ت}\end{array}$ & 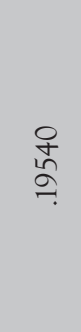 & $\begin{array}{l}\text { ㅇ } \\
\stackrel{0}{0} \\
\stackrel{5}{+}\end{array}$ & 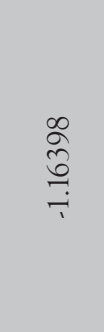 & 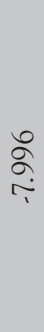 & $\vec{m}$ & 8 \\
\hline
\end{tabular}

Brand Familiarity

Table 3:

\begin{tabular}{|c|c|c|c|c|c|c|c|c|c|}
\hline \multicolumn{10}{|c|}{ Paired Samples Test } \\
\hline & & \multicolumn{5}{|c|}{ Paired Differences } & \multirow[b]{2}{*}{$\mathrm{t}$} & \multirow[b]{2}{*}{$\mathrm{df}$} & \multirow[b]{2}{*}{$\begin{array}{l}\text { Sig. } \\
\text { (2-tail } \\
\text { ed) }\end{array}$} \\
\hline & & \multirow[t]{2}{*}{ Mean } & \multirow[t]{2}{*}{$\begin{array}{l}\text { Std. } \\
\text { Devia- } \\
\text { tion }\end{array}$} & \multirow[t]{2}{*}{$\begin{array}{l}\text { Std. } \\
\text { Error } \\
\text { Mean }\end{array}$} & \multicolumn{2}{|c|}{$\begin{array}{l}95 \% \text { Confidence } \\
\text { Interval of the } \\
\text { Difference }\end{array}$} & & & \\
\hline & & & & & Lower & Upper & & & \\
\hline $\begin{array}{c}\text { Pair } \\
1\end{array}$ & $\begin{array}{l}\text { Prerecog - } \\
\text { Postrecog }\end{array}$ & 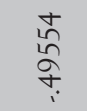 & $\frac{\mathfrak{o}}{\underset{\tau}{\tau}}$ & $\begin{array}{l}\infty \\
\stackrel{0}{N} \\
\infty \\
0\end{array}$ & 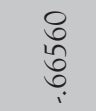 & 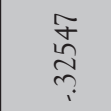 & $\begin{array}{l}\text { qे } \\
\text { iे }\end{array}$ & $\bar{n}$ & 8 \\
\hline
\end{tabular}

Brand Recognition 
brand salience frame work/scale as the outcome of product placement in the context of movies. While the study has used a cartoon movie clip to investigate the efficacy of product placement, we suggest considering it as a rousing track of research and empirical investigation on product placement. More insightful methods, procedures and real life experiments will enhance the significance and practical implications of the findings.

\section{Limitations and Future Research:}

Although the outcomes point to a much specific and tangible product placement understandings regarding its effect on brand salience, several other limitations can also be identified to this research. First, controlling for all of the variables in Logorama may appear hard, as the movie clip is made for a general marketing context, while the study used it in a further very narrowly defined context. The measurement tool for brand placement may also require modification and reconsideration for effective collection of information that is specific to the memory reactivation process of target consumers.

The process of recovering low involvement commodity brand from memory might be different high involvement durable brands' recall. For the low involvement brands, a comparison of responses before and after exposure can show and wrap the central effects of product placement. High involvement brands however, may not be accurately measured by pre and post-exposure response measures comparison. Future research should focus on developing and validating a reliable scale for brand salience that has either the ability to exclude and minimize all the deteriorations caused by irrelevant variables or has the ability to incorporate them.

\section{References:}

Babin, Laurie A., and Sheri T. Carder (1996), "Advertising via the Box Office: Is Product Placement Effective?" Journal of Promotion Management, 3 (1/2), 31-51.

d'Astous, A., \& Chartier, F. (2000). A study of factors affecting consumer evaluations and memory of product placements in movies. Journal of Current Issues and Research in Advertising, 22(2), 31-40.

de Gregorio, F., \& Sung, Y. (2004). "Pass the Courvoisier”: An exploratory study of brand mentions in popular songs. In Rose, P. (Ed.).

Annual Conference of the American Academy of Advertising. North Miami, FL: American Academy of Advertising, p. 117.

DeLorme, Denise E., and Leonard N. Reid (1999), “Moviegoers' Experiences and Interpretation of Brands in Films Revisited," Journal of Advertising, 28 (2), 71-95. 
Evangelista, B. (1999, January 18). Advertisers now getting into video games. San Francisco Chronicle, E1. Ferraro, R., \& Avery, R. J. (2000). Brand appearances on prime-time television. Journal of Current Issues and Research in Advertising, 22(2), 1-15.

Galician, M.-L. (Ed.). (2004). Handbook of product placement in the mass media: New strategies in marketing theory, practice, trends, and ethics. New York: Best Business Books/Haworth Press.

Gupta, P. B., \& Gould, S. J. (1997). Consumers' perceptions of the ethics and acceptability of product placement in movies: Product category and individual differences. Journal of Current Issues and Research in Advertising, 19(1), 37-50.

Gould, S. J., Gupta, P. B., \& Grabner-Krauter, S. (2000). Product placements in movies:Across-cultural analysis of Austrian, French, and American consumers' attitudes' toward this emerging international promotional medium. Journal of Advertising, 29(4), 41-58.

Hawkins, S. A., \& Hoch, S. J. (1992). Low-involvement learning: Memory without evaluation. Journal of Consumer Research, 19, 212-225.

Holden, S. J. S., \& Vanhuele, M. (1999). Know the name, forget the exposure: Brand familiarity versus memory of exposure context. Psychology and Marketing,16, 479-496.

Howard-Williams, P. (1993). Cinema’s ten-year bounce-back. Admap, December.

Janiszewski, C. (1993). Preattentive mere exposure effects. Journal of Consumer Research, 20, 376-392.

Karrh, J. A., Frith, K. T., \& Callison, C. (2001). Audience attitudes towards brand (product) placement: Singapore and the United States. International Journal of Advertising, 20(1), 3-24.

Krishnan, H. S., \& Chakravarti, D. (1999). Memory measures for pretesting advertisments: An integrative conceptual framework and a diagnostic template. Journal of Consumer Psychology, 8(1), 1-37.

Law, S., Hawkins, S. A., \& Craik, F. I. M. (1998). Repetition-induced belief in the elderly: Rehabilitating age-related memory deficits. Journal of Consumer Research, 25, 95-107.

Law and Braun. (2000). Impact of Product Placement. Psychology \& Marketing, Vol. 17(12):1059-1075

Lehu, J.-M. (2007). Branded entertainment: Product placement \& brand strategy in the entertainment business. London and Philadelphia: Kogan Page.

Mckechnie, S. A., \& Zhou, J. (2003). Product placement in movies: A comparison of Chinese and American consumers' attitudes. International Journal of Advertising, 22(3), 349-374.

Newell, Jay, Charles T. Salmon, and Susan Chang (2006), "The Hidden History of Product Placement," Journal of Broadcasting and Electronic Media, 50 (4), 575-594.

Reed, J. D. (1989, January 2). Plugging away in Hollywood. Time, p. 103.

Rossler, P., \& B"acher, J. (2002). Transcultural effects of product placement in movies. Zeitschrift f "ur 
Medienpsychologie, 14(3), 98-108.

Russell, C. A. (1998). Toward a framework of product placement: Theory propositions. Advances in Consumer Research, 25(1), 357-362.

Russell, C. A. (2002). Investigating the effectiveness of product placements in television shows: The role of modality and plot connection congruence on brand memory and attitude. Journal of Consumer Research, 29(3), 306-318.

Schacter, D. L. (1987). Implicit memory: History and current status. Journal of Experimental Psychology: Learning, Memory, and Cognition, 13, 501-518.

Steorz, E. M. (1987). The cost efficiency and communication effects associated with brand name exposure within motion pictures. Unpublished master's thesis. Morgantown, WV: West Virginia University. Sung, Y. \& Gregorio, F.D. (2008). New Brand Worlds: College Student Consumer Attitudes toward Brand Placement in Films, Television Shows, Songs, and Video Games, Journal of Promotion Management, 14:1-2, 85-101.

Vollmers, S., \& Mizerski, R. (1994). A review and investigation into the effectiveness of product placement in films. In King, K. W. (Ed.), Proceedings of the 1994 Conference of the American Academy of Advertising. Athens, GA: American Academy of Advertising, pp. 97-102.

Wasko, J., Phillips, M., \& Purdie, C. (1993). Hollywood meets Madison Avenue: The commercialization of U.S. films. Media, Culture, and Society, 15(2), 271-293. 